\title{
PERANCANGAN APLIKASI PUSH NOTIFICATION BERBASIS ANDROID
}

\author{
Mohd. Siddik ${ }^{1}$, Akmal Nasution ${ }^{2}$ \\ ${ }^{1,2}$ Program Studi Sistem Komputer, STMIK Royal Kisaran \\ e-mail: mohdsiddik27@gmail.com ${ }^{1}$, nst.akmal@gmail.com ${ }^{2}$
}

\begin{abstract}
Push Notification is a service that is widely used for the purposes of notification via short messages on the smartphone. With the Push Notification service, users can be helped in terms of short notice notification. In the implementation of Push Notification can be utilized in various daily needs such as attendance monitoring, latest news updates, and so forth. Application to be designed is an application that can send Push Notification which will be able to diembangkang in various fields according to user needs. Lack of knowledge in providing information in real time, resulting in information submitted is not up-to-date, so that in various situations and conditions of information provided has been obsolete. Push Notification is one service that can answer the problem so that no more information is not delivered the latest, with the use of this service every update information will be immediately sent as a message notification, so the latest information will not be missed. Push Notification Services are generally widely applied to mobile applications such as Android and iOS. For the use of the largest mobile operating system based on statcounter for 2012 to 2016 in Indonesia is controlled by the Android Operating System. Based on the data the application development Push Notification is applied to the Andoid Operating System as the largest market share today.
\end{abstract}

Keywords: Applications, Push Notification, Mobile, Android.

\begin{abstract}
Abstrak: Push Notification adalah sebuah layanan yang banyak digunakan untuk keperluan pemberitahuan melalui pesan pendek yang ada di smartphone. Dengan adanya layanan Push Notification tersebut, pengguna dapat terbantu dalam hal yang bersipat pemberitahuan secara singkat. Pada implementasinya Push Notification dapat dimanfaatkan dalam berbagai keperluan sehari-hari misalnya untuk monitoring absensi, update berita terbaru, dan sebagainya. Aplikasi yang akan dirancang adalah sebuah aplikasi yang dapat mengirim Push Notification yang nantinya akan dapat dikembangkang di berbagai bidang sesuai dengan kebutuhan pengguna. Kurangnya pengetahuan dalam memberikan informasi secara real time, berakibat informasi yang tersampaikan tidak up-to-date, sehingga dalam berbagai situasi dan kondisi informasi yang diberikan telah usang. Push Notification salah satu layanan yang dapat menjawab masalah tersebut sehingga tidak ada lagi informasi yang terbaru tidak tersampaikan, dengan penggunaan layanan ini setiap terjadi update informasi maka akan langsung terkirim sebagai pesan notification, sehingga informasi yang terbaru tidak akan terlewatkan. Layanan Push Notification umumnya banyak diterapkan pada aplikasi mobile seperti Android dan IOS. Untuk penggunaan Sistem Operasi mobile terbesar berdasarkan statcounter untuk tahun 2012 sampai 2016 di Indonesia dikuasi oleh Sistem Operasi Android. Berbasarkan data tersebut pengembangan aplikasi Push Notification ini diterapkan pada Sistem Operasi Andoid sebagai pangsa pasar terbesar saat ini.
\end{abstract}

Kata Kunci: Aplikasi, Push Notification, Mobile, Android. 
Available online at http://jurnal.stmikroyal.ac.id/index.php/jurteksi

\section{PENDAHULUAN}

Perkembangan teknologi saat ini semakin pesat, khususnya kemajuan di bidang teknologi informasi terutama pada teknologi mobile dan internet. Penggunaan aplikasi mobile dan web dikatakan lebih efektif dan efisien karena adanya kemudahan dalam pengaksesan dan peyampaian informasi. Untuk penyampaian informasi secara real time saat ini dapat menggunakan layanan Push Notification.

Push Notification adalah sebuah layanan yang banyak digunakan untuk keperluan pemberitahuan melalui pesan pendek yang ada di smartphone. Dengan adanya layanan Push Notification tersebut, pengguna dapat terbantu dalam hal yang bersipat pemberitahuan secara singkat. Pada implementasinya Push Notification dapat dimanfaatkan dalam berbagai keperluan sehari-hari misalnya untuk monitoring absensi, update berita terbaru, dan sebagainya. Aplikasi yang akan dirancang adalah sebuah aplikasi yang dapat mengirim Push Notification yang nantinya akan dapat dikembangkang di berbagai bidang sesuai dengan kebutuhan pengguna. Kurangnya pengetahuan dalam memberikan informasi secara real time, berakibat informasi yang tersampaikan tidak up-todate, sehingga dalam berbagai situasi dan kondisi informasi yang diberikan telah usang. Push Notification salah satu layanan yang dapat menjawab masalah tersebut sehingga tidak ada lagi informasi yang terbaru tidak tersampaikan, dengan penggunaan layanan ini setiap terjadi update informasi maka akan langsung terkirim sebagai pesan notification, sehingga informasi yang terbaru tidak akan terlewatkan. Layanan Push Notification umumnya banyak diterapkan pada aplikasi mobile seperti Android dan IOS. Untuk penggunaan Sistem Operasi mobile terbesar berdasarkan statcounter untuk tahun 2012 sampai 2016 di Indonesia dikuasi oleh Sistem Operasi
Android.

Berbasarkan data tersebut pengembangan aplikasi Push Notification ini diterapkan pada Sistem Operasi Andoid sebagai pangsa pasar terbesar saat ini. Adapun masalah pada penelitian ini adalah bagaimana menerapkan Push Notification pada Aplikasi berbasis Android, Bagaimana membangun aplikasi Android yang dilengkapi dengan teknologi Push Notification. Dan baaimana dengan teknologi Push Notification berbasis android dapat menyampaikan informasi secara real time.

Agar lebih terarahnya pembahasan sesuai dengan topik yang dibahas, maka perlu dilakukan pembatasan yaitu, Penelitian ini membahas tentang penerapan Push Notification berbasis android, Aplikasi Push Notification yang dibangun hanya sebagai model pesan, yang dikirim sebagai Notification pada Android.

Adapun tujuan penelitian ini adalah, Membangun aplikasi yang dapat mengirim pesan Notification dengan teknologi Push Notification, Menerapkan teknologi Push Notification pada aplikasi yang dibangun, serta bermanfaat memberikan gambaran secara individu terhadap penggunaan Teknologi teknologi Push Notification, Memberikan kontribusi dalam layanan pemberian informasi secara real time bagi pengguna.

Android merupakan suatu software (perangkat lunak) yang digunakan pada mobile device (perangkat berjalan) yang meliputi sistem operasi, middleware, dan aplikasi inti. Android Standart Development Kit (SDK) menyediakan alat dan Application Programming Interface (API) yang diperlukan untuk memulai pengembangan aplikasi pada platform Android menggunakan bahasa pemrograman Java, yaitu kode Java yang terkompilasi dengan data dan file resources yang dibutuhkan aplikasi dan digabungkan oleh app tools menjadi paket Android. File tersebut 
ditandai dengan ekstensi .apk. File inilah yang didistribusikan sebagai aplikasi dan diinstal pada perangkat mobile. (Safaat, 2012).

Untuk dapat mengimplementasi-
kan layananan Push Notification diperlukan cloud server, salah satu cloud server yang bias digunakan adalah Fire Base. Fire Base adalah layanan pada Google Cloud Messaging (GCM) yang membantu pengembang mengirim data dari server untuk aplikasi mereka Android pada perangkat Android. Ini bisa menjadi pesan ringan memberitahu aplikasi Android bahwa ada data baru yang akan diambil dari server (misalnya, film diunggah oleh seorang teman), atau bisa juga pesan yang berisi sampai dengan 4KB data payload (sehingga aplikasi seperti instant messaging dapat mengkonsumsi pesan langsung). Layanan GCM menangani semua aspek antrian pesan dan pengiriman ke aplikasi target Android berjalan pada perangkat target. GCM memungkinkan aplikasi android untuk mngirimkan pesan kepada server untuk membroadcast sebuah notifikasi kepada seluruh client yang ada. Hanya membutuhkan sebuah account Gmail maka akan langsung dapat menggunakan fasilitas GCM ini. (Santoso, 2012).

\section{METODOLOGI}

Metodologi penelitian merupakan urutan dalam melakukan penelitian. Dimaksudkan agar penelitian lebih terkonsep dan terarah sesuai tujuan yang ingin dicapai, sehingga mengahasilkan sistem yang telah teruji dan dapat memecahkan permasalahan yang diteliti. Pada Metodologi penelitian ini digambarkan kedalam bentuk sebuah kerangka kerja penelitian dimulai dari mengidentifikasai masalah, menganalisa masalah, menentukan tujuan, studi literatur, mengumpulan data, analisis data sampai pada mengevaluasi akhir pada penelitian ini.

\section{Kerangka Kerja Penelitian}

Tahapan ini menggambarkan proses kerja penelitian dimulai dari tahap awal sampai mencapai tujuan akhir penelitian. Adapun kerangkan kerja penelitan ini terlihat pada gambar 1 berikut:

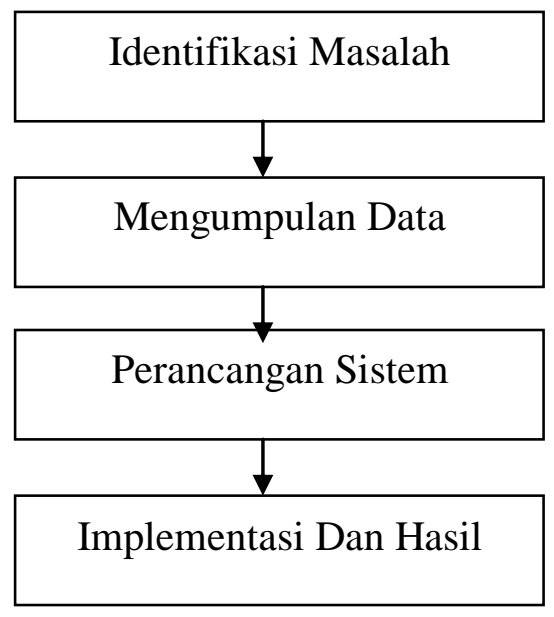

Gambar 1. Kerangka Kerja Penelitian

\section{Identifikasi Masalah}

Pada tahapan ini melakukan identifikasi masalah terhadap implementasi push notification berbasis Android.

\section{Pengumpulan Data}

Pada Tahapan ini dilakukan pengumpulan terhadap studi literature, serta referensi-referensi yang berhubungan dengan penelitian yang dilakukan.

\section{Perancangan Sistem}

Pada tahap perancangan sistem dilakukan dengan terlebih dalu menggambarkan model rancangan pada sistem yang nantinya akan dimodelkan menggunakan diagram UML yaitu; Use Case Diagram, Activity diagram

\section{Implementasi Dan Hasil}

Pada tahapan ini melakukan implementasi dan hasil pada rancangan sistem yang telah dilakukan. 


\section{HASIL DAN PEMBAHASAN}

\section{Perancangan Sistem}

Perancangan sistem dilakukan dengan terlebih dalu menggambarkan model rancangan pada sistem menggunakan diagram UML yaitu; Use Case Diagram, Activity diagram terlihat pada gambar berikut:

\section{Use Case Diagram}

Use Case Diagram pada penelitian ini menggambarkan hubungan antar actor dengan sistem dalam hal fungsional. Adapun rancangan Use Case Diagram dapat dilihat pada gambar berikut:

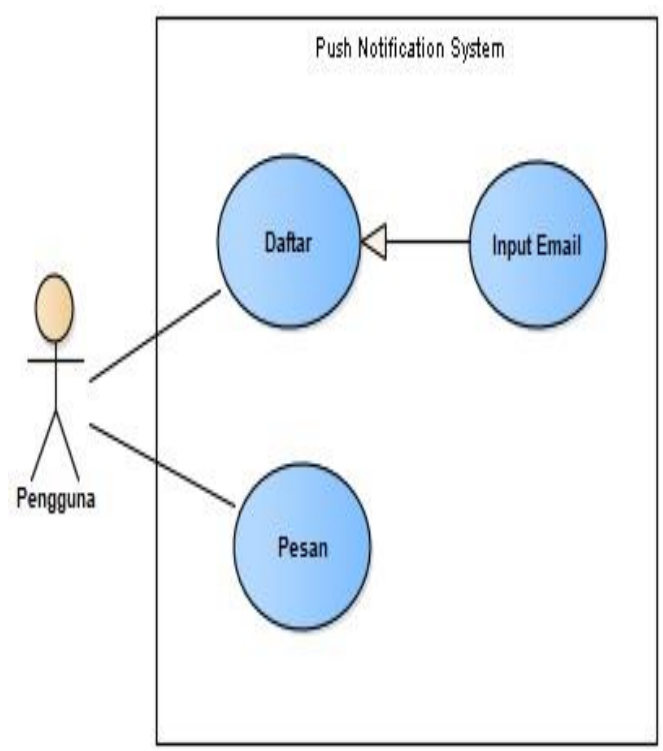

Gambar 2. Use Case Diagram

\section{Activity Diagram}

Activity Diagram pada penelitian ini menggambarkan aliran kerja aktivitas sistem mulai dari awal sampai akhir. Adapun rancangan Activity Diagram tertuang dalam gambar 2 .

\section{Implementasi}

Pada tahapan ini dilakukan implementasi dan hasil sistem mulai dari registrasi email oleh pengguna, akses menu cloud massaging pada firebase, selanjutnya masuk pada halaman send your first message, dan pengisian pesan pada form compose message. Tahap registrasi dilakukan dengan menginput email pengguna pada gambar 3 .

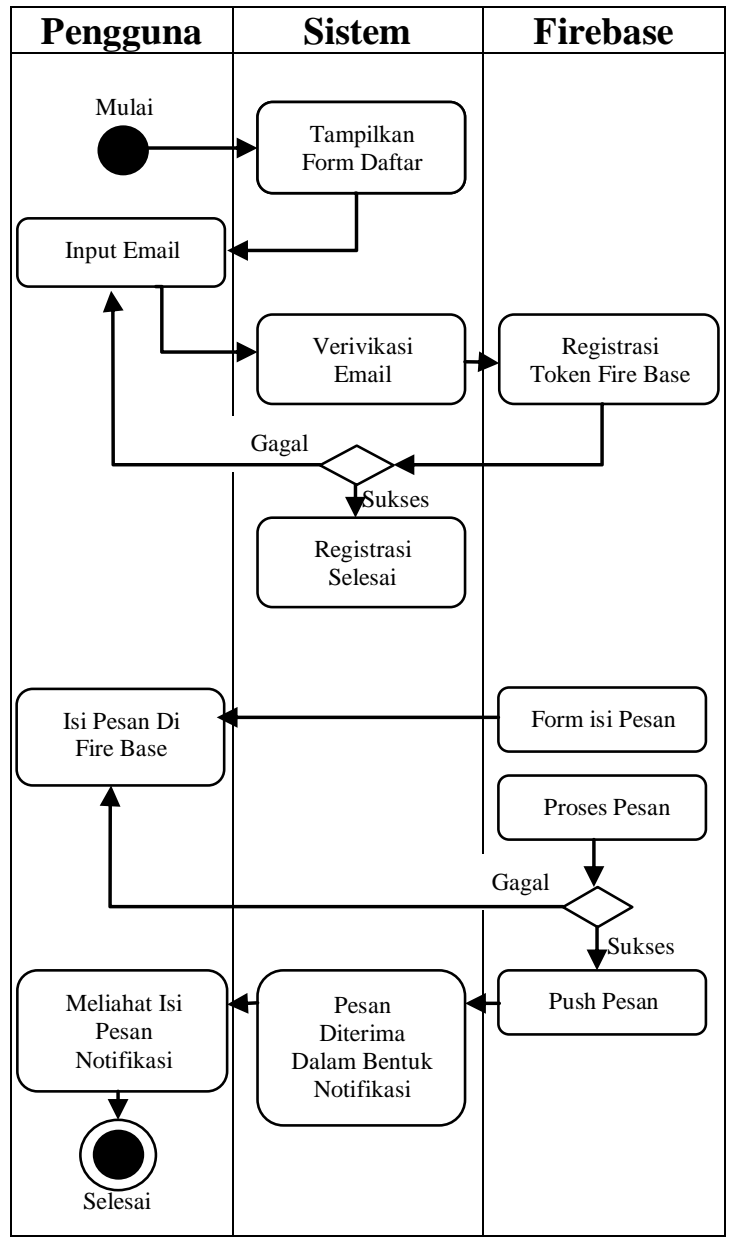

Gambar 2. Activity Diagram

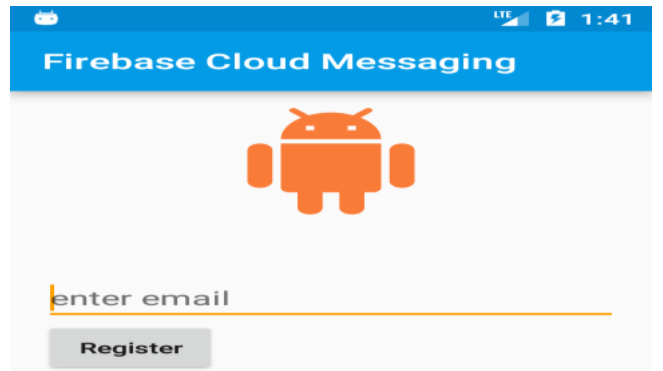

Gambar 3. Registrasi Email Fire Base

Email yang diinput akan diproses pada firebase bersama dengan token aplikasi. Tahap selanjutnya pengguna dapat langsung membuka firebase console. Pada firebase console pilih menu 
cloud massaging terlihat pada gambar 4 berikut:

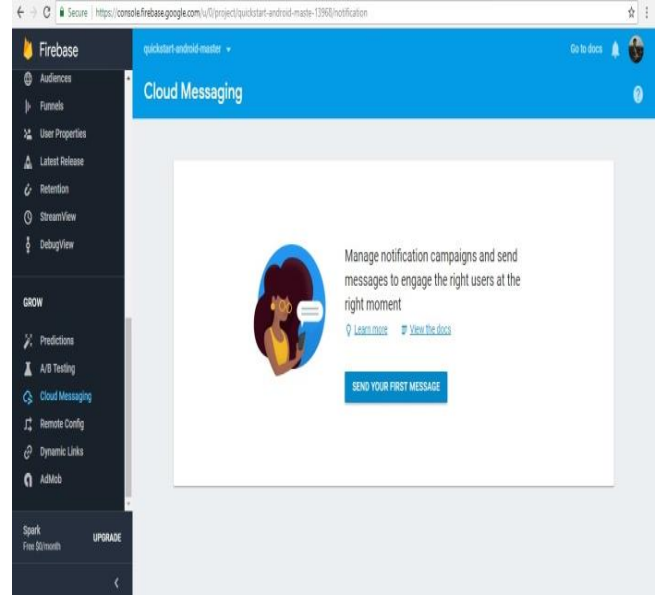

Gambar 4. Cloud Fire base

Selanjutnya masuk pada halaman compose massage untuk mengisi pesan yang akan dikirim, adapun proses tersebut dapat terlihat pada gambar 5 .

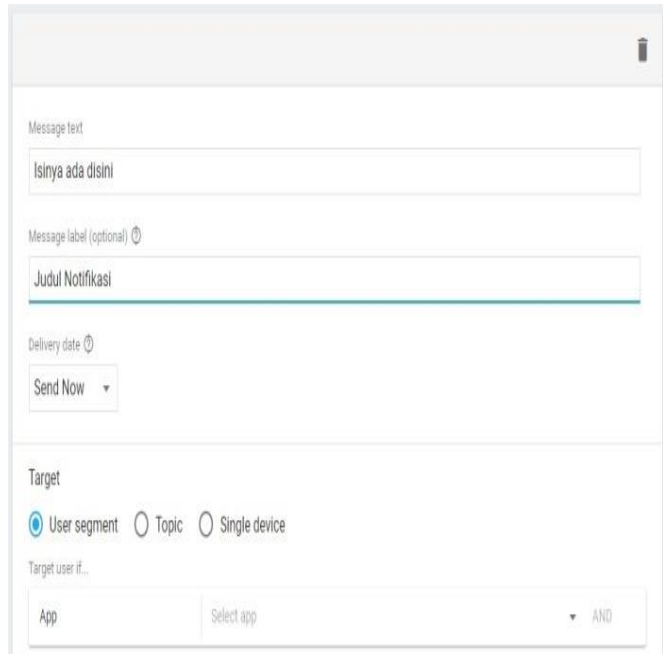

Gambar 5. Compose Massage

Informasi pesan masuk dapat terlihat pada icon notification pada prangkat mobile android, seperti yang terlihat pada gambar 6 .

Untuk melihat pesannya dapat melakukan swife pada layar mobile android, dan pesan akan terlihat seperti pada gambar 7

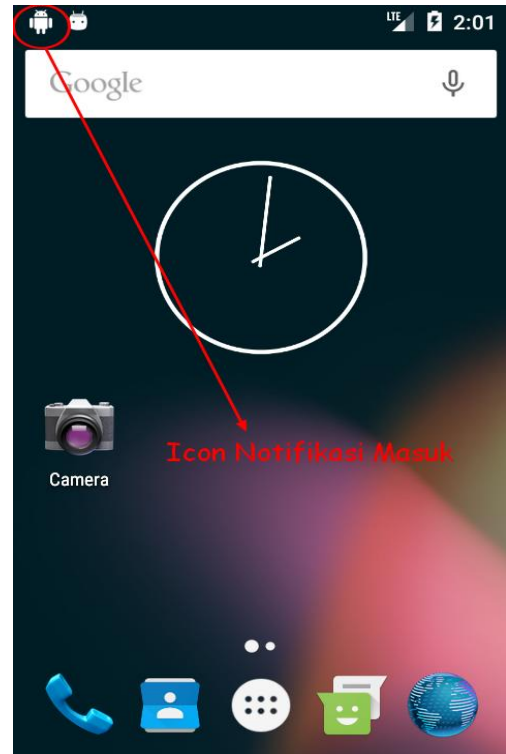

Gambar 6. Notifikasi

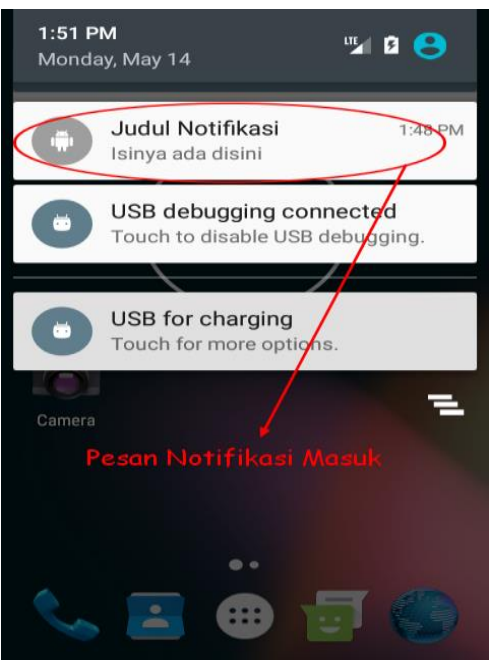

Gambar 7. Pesan Notifikasi

\section{SIMPULAN}

Berdasarkan pada pembahasan dapat diambil kesimpulan sebagai berikut:

1. Aplikasi push notification dapat berjalan dengan baik.

2. Pesan notification dapat terkirim kepada pengguna.

3. Klient pengguna dapat melihat isi pesan notification notifikasi yang dikirim. 


\section{UCAPAN TERIMA KASIH}

Ucapan terima kasih sebesarbesarnya atas pendanaan penelitian dan pubilkasi yang dibiayai oleh Direktorat Riset dan Pengabdian Masyarakat

\section{DAFTAR PUSTAKA}

Kadir. A. (2014). Pemrograman Aplikasi Android Yogyakarta: Andi Publisher.

Jefferson Setiawan., Edy Kristianto., dan Fredicia., (2015). Implementasi Push Notification Pada Informasi Perkuliahan dan Kegiatan Mahasiswa Berbasis Android. 4 (14).

Khan, S.I., and Patil, Y. S. (2016). Google Cloud Messaging (GCM). International Journal of Innovative and Emerging Research in Engineering 3 (2)

Siddik, M. (2017). IMPLEMENTASI MIKROTIK ROUTER BOARD 750 SEBAGAI FIREWALL BLOK SITUS PADA JARINGAN
Direktorat Jenderal Penguatan Riset dan Pengembangan Kementerian Riset, Teknologi dan Pendidikan Tinggi sesuai dengan Kontrak Penelitian Tahun Anggaran 2018.

LAN. JURTEKSI ROYAL VOI 3 No $2,3$.

Yavuz Selim Yilmaz., Bahadir Ismail., and Aydin Murat Demirbas., (2014). "Google Cloud Messaging (GCM): An Evaluation" Globecom 2014 - Symposium on Selected Areas in Communications : GC14 SAC Internet of Things.

Zamrony P. Juhara., (2016). "Panduan Lengkap Pemrograman Android", Andi Publisher, Yogyakarta 